\title{
A Conexão Americana: Mattoso Câmara e o Círculo LINGÜÍstico DE Nova IorQue*
}

\author{
(The American Connection: Mattoso Câmara and the \\ New York Linguistic Circle)
}

\author{
Cristina Altman \\ (CEDOCH/ DL-USP)
}

\begin{abstract}
When mention is made of Brazil in connection with American linguistics, it usually amounts to a reference to the Linguistic Circle of New York, where Roman Jakobson (1896-1982) and Claude Lévi-Strauss (b. 1908) - who bad recently come from Brazil where he stayed from 1935 until 1939 - met and exchanged ideas. This singular event has cast a shadow on other contacts between Brazil and American linguistics, among which the one between Jakobson and the Brazilian linguist Joaquim Mattoso Câmara (1904-1970) was much more consequential, at least in what concerns the implementation of structural linguistics in Brazil and in South America during the 1950s and the 1960s. The impact of Jakobson and of American Linguistics on the
\end{abstract}

\footnotetext{
* O tema do presente artigo foi várias vezes por mim retomado em passado recente. Uma primeira versão bastante menor das questões aqui expostas foi apresentada durante o colóquio da North American Association for the History of the Language Sciences, realizado em Los Angeles, em janeiro de 1999, concomitantemente à reunião anual da Linguistic Society of America, que celebrava, naquela ocasião, seu $75^{\circ}$. aniversário. Uma segunda visita ao tema, bastante ampliada e modificada, foi apresentada em 6 de maio do mesmo ano no Departamento de Lingüística e Filosofia do MIT, sob o título: "The Early Days of the 'Cercle Linguistique de New York' - Jakobson, LéviStrauss and others in the eyes of a Brazilian Linguist" e publicada pela primeira vez no periódico Historiografia Lingüística, 26:3. 355-382. (Amsterdam, 1999.) Voltei ao assunto ainda uma vez na minha tese de livre-docência (São Paulo USP, 2000) e é a partir desta última versão, inédita, que elaborei o presente texto para homenagear o centenário de Mattoso Câmara, junto a uma ilustre plêiade de lingüistas brasileiros ligados ao velho mestre por relações de trabalho e afeto. A eles meus agradecimentos pela colaboração. Sou também grata à Pontifícia Universidade Católica de Petrópolis. Biblioteca e Arquivo do Professor Joaquim Mattoso Câmara Jr. - em especial a Maria das Neves Krüger, bibliotecária da Universidade e a José Ferrari Neto, arquivista da mesma instituição - às MIT Libraries. Institute Archives and Special Collections: Roman Jakobson's Collection, em Cambridge, Mass., pela permissão de examinar os documentos e os manuscritos de ambos os lingüistas ali depositados.
} 
work of Mattoso Câmara and its subsequent influence on developments of Brazilian linguistics are the focus of the article.

KEY-WORDS: Linguistic Circle of New York; Jakobson; Structuralism.

Resumo: Quando se pensa nas conexões entre as lingüísticas brasileira e norteamericana, a primeira referência que nos vem à mente é o Círculo Lingüístico de Nova Iorque, onde Roman Jakobson (1896-1982) e Claude Lévi-Strauss (n. 1908) recém chegado do Brasil, onde permanecera entre 1935 e 1939 - se encontraram e discutiram suas idéias. Este encontro excepcional obscureceu outros contatos entre a lingüística brasileira e a norte-americana, entre eles, aquele ocorrido entre Jakobson e o lingüista brasileiro Joaquim Mattoso Câmara Jr. (1904-1980), que teve conseqüências bem maiores, ao menos no que diz respeito à implementação da lingüística estrutural no Brasil e na América do Sul nos anos 50 e 60. O impacto de Jakobson e da lingüística norte-americana no trabalbo de Mattoso Câmara e sua subseqüente influência no desenvolvimento da lingüística brasileira são o foco do presente artigo.

PaLAVRAS-CHAVE: Círculo Lingüístico de Nova-Iorque; Jakobson; Estruturalismo.

\section{Introdução}

Quando se pensa nas relações entre as lingüísticas brasileira e americana, logo vem à mente o Círculo Lingüístico de Nova Iorque, criado em 1943 como uma extensão da École Libre des Hautes Études, organizada na cidade de Nova Iorque por um grupo de scholars belgas e franceses, refugiados da Europa nazista. Patrocinada pela New School for Social Research, a École Libre oferecia vários cursos em humanidades, e foi aí que Roman Jakobson (1896-1982) proferiu pela primeira vez, entre maio e junho de 1942, suas conferências sobre 'o som e o sentido', celebradas em história da lingüística mais pela influência que exerceram do que, eventualmente, pelo seu conteúdo (cf. Joseph 1989, Falk 1995a). Essas conferências atraíram uma ampla audiência de jovens e talentosos lingüistas, como Paul L. Garvin (1919-1994), Charles F. Hockett (n. 1916), Thomas A. Sebeok (n. 1920), Henry M. Hoenigswald (n. 1915), Joaquim Mattoso Câmara (19041970), e outros colegas da École, como o antropólogo francês Claude LéviStrauss (n. 1908), então secretário geral do Centre d'Études et d'Informations pour les Relations avec l'Amérique Centrale et l'Amerique du Sud.

Lévi-Strauss havia estado em vários lugares do Brasil entre 1935 e 1939 fazendo pesquisas etnológicas, inclusive em São Paulo, onde participou da fundação da Faculdade de Filosofia da Universidade de São Paulo, 
em 1934. De volta à França no momento em que eclodiu a II Guerra Mundial, Lévi-Strauss foi convidado a trabalhar na New School for Social Research na cidade de Nova Iorque, como parte do projeto de resgate da Fundação Rockfeller dos pesquisadores ameaçados pela ocupação alemã (cf. Lévi-Strauss 1974:23). Na École Libre, encontrou Roman Jakobson pela primeira vez e é o próprio Lévi-Strauss (1977[1976]: xii), em retrospectiva, quem melhor descreve a transformação que a fonologia de Praga operou no seu pensamento antropológico: “... instead of losing one's way among the multitude of different terms the important thing is to consider the simpler and more intelligible relations by which they are interconnected" [em vez de nos perdermos em meio a uma multidão de termos diferentes, o importante é considerar as relações, mais simples e mais inteligíveis, que os interconectam].

Não se pode negar, evidentemente, que a transposição operada por Lévi-Strauss do conceito de fonema e estrutura a outros domínios teve conseqüências metodológicas bastante importantes no âmbito mais geral das ciências sociais (v. Joseph 1989, Waugh \& Burston 1990). Mas, enquanto tal, este fato acabou por desviar a atenção de alguns historiógrafos contemporâneos de outras relações entre a lingüística que se fazia na América e a lingüística que se fazia no Brasil, talvez igualmente importantes no que diz respeito à implantação da lingüística estrutural na América do Sul, nas décadas de 50 e 60.

Com efeito, o encontro de Jakobson e Mattoso Câmara em Nova Iorque no início da década de 1940 levou Mattoso a aderir à análise sincrônica, com a qual ele tinha tomado contato anteriormente através da leitura do Cours (1916) de Saussure, da Language (1921) de Sapir e Die phonologischen Vokalsysteme (1929) de Trubetzkoy, textos a que freqüentemente se referia nas aulas sobre lingüística estática que deu no Rio de Janeiro em 1938 (França 1995). Publicadas em série pela Revista de Cultura, essas aulas foram publicadas em livro em 1941 sob o título de Princípios de Lingüística Geral como Fundamento para os Estudos Superiores da Lingua Portuguesa, o primeiro manual de 'lingüística moderna' escrito em português, pelo menos até os anos 60 (cf. Llorach 1962 e Saporta 1960).

Durante sua estada nos Estados Unidos em 1943-1944, Mattoso Câmara assistiu às conferências de Jakobson em lingüística geral, tanto na École Libre, quanto na Universidade de Colúmbia, e seguiu cursos de sânscrito com um certo Anthony Paura, de grego com Fred W. Householder (1913-1994), e de línguas africanas com George Herzog (1901-1983). 
Mattoso Câmara, entretanto, parecia mais interessado no trabalho dos scholars que gravitavam ao redor de Jakobson e do Círculo Lingüístico de Nova Iorque, como Morris Swadesh (1909-1967) e Louis Herbert Gray (18751955). Não exclusivamente, porém, uma vez que ele também procurou estabelecer contato com outros lingüistas a quem visitou na ocasião: Yale, onde encontrou Leonard Bloomfield (1887-1949), Edgar H. Sturtevant (1875-1952) e Franklin Edgerton (1885-1967); Pennsylvania, onde encontrou Zellig S. Harris (1902-1992), e Chicago, onde estudou fonética experimental com Clarence Parmenter (1888-1982). Como Naro (1972:viii-ix) observara, Mattoso preferiu contatar a 'velha guarda' dos lingüistas americanos. De fato. Mas talvez fosse o caso de também lembrar que muitos dos lingüistas americanos mais jovens estavam em serviço militar à época, não necessariamente fora do país, mas, certamente, fora dos principais centros universitários pelos quais Mattoso Câmara circulou, o que dificultava qualquer tipo de intercâmbio.

Seja como for, parte das atividades de Mattoso Câmara nos Estados Unidos, notadamente os cursos que seguiu na École Libre e em Colúmbia, foram disciplinadamente registrados por ele em um caderno, conservado hoje na Universidade Católica de Petrópolis. Suas anotações atestam não somente quão profundamente ele absorveu a concepção de estrutura lingüística de Jakobson, mas também o quanto a vida intelectual americana dos anos 1940 o influenciou (v. Mattoso Câmara 1945). Com efeito, logo após sua primeira imersão no estruturalismo de Praga, Mattoso propôs, em 1949, como tese de doutoramento, uma descrição fonêmica do português do Brasil, a primeira, publicada logo depois, em 1953, com o título de Para o estudo da fonêmica portuguesa (Mattoso Câmara 1949a e b; 1953a). Além disso, ele revisou e atualizou seus Princípios pelo menos mais três vezes (em 1954, 1959 e 1967), introduzindo, desta maneira, várias gerações de alunos brasileiros e sul-americanos nos fundamentos da lingüística estrutural.

\section{Dois lingüistas no exílio}

\subsection{Mattoso Câmara}

Mattoso Câmara é considerado hoje o principal proponente da lingüística 'moderna' no Brasil e o primeiro scholar brasileiro a propor uma descrição estrutural do português do Brasil. 
Originalmente formado em arquitetura e direito, nos trinta anos da sua produtiva carreira (mais do que trinta, se computarmos também suas atividades nas escolas secundárias do Rio de Janeiro desde 1928), Mattoso Câmara escreveu muitos livros, alguns publicados postumamente, com base nos manuscritos e anotações que preparara para as aulas e conferências que proferiu no Brasil e em alguns outros países. Suas publicações revelam o largo espectro do seu interesse lingüístico que ia desde a lingüística geral (1941, 1954, 1959); lingüística descritiva (1949a, b, 1953a, 1969, 1970, 1972); estilística (1953b), que, para ele, era um ramo da lingüística estrutural; até as línguas indígenas brasileiras (1965) e a história da lingüística (1975). Seu legado inclui vários outros textos, resenhas, artigos, prefácios, notas, relatórios, artigos de jornais, e traduções (v. Naro \& Reighard 1972, Uchôa 1972), sem mencionar inúmeros outros materiais não publicados, e a copiosa correspondência (c. 3000 cartas), conservados hoje e disponíveis para consulta em Petrópolis.

A visita de Mattoso Câmara a Nova Iorque em 1943 resultou de importantes mudanças no cenário acadêmico brasileiro alguns anos antes. Em 1939, o governo de Getúlio Vargas fechou a Faculdade de Filosofia do Rio de Janeiro, poucos meses depois de Mattoso inaugurar seu curso de lingüística geral, e fundou, em seu lugar, uma instituição mais conservadora que não incluiu a 'nova' disciplina lingüística em seu currículo. Como resultado, Mattoso perdeu seu lugar na Universidade (cf. Rodrigues 1984).

Este fato teria importantes conseqüências para a institucionalização da lingüística no Brasil. Eliminar a lingüística geral do currículo das faculdades de Letras significava, na prática, eliminar todo um conjunto de problemas e metodologias inovadoras no tratamento da linguagem da formação de jovens profissionais que, pela primeira vez no país, se graduavam em cursos de língua e literatura. As futuras gerações de lingüistas brasileiros estavam indelevelmente fadadas, de antemão, a perder o bonde da história.

Fora da universidade, Mattoso Câmara recebeu apoio institucional do setor de Antropologia do Museu Nacional do Rio de Janeiro, à época um instituto de pesquisa autônomo, dedicado à pesquisa etnológica e antropológica. Foi através do Museu que Mattoso Câmara viajou aos Estados Unidos entre setembro de 1943 e abril de 1944, com uma bolsa da Fundação Rockfeller. De acordo com seu relatório de viagem de 1944, ele estava principalmente interessado em lingüística indo-européia, psicologia da 
linguagem, e, em menor grau, conforme suas palavras, em fonética experimental, línguas indígenas e africanas (apud França 1998). Como sabemos hoje, seu real interesse acabou sendo a lingüística geral de Jakobson.

\subsection{Roman Jakobson}

Roman Jakobson chegou à cidade de Nova Iorque em 4 de junho de 1941, dois anos antes de Mattoso Câmara, e em circunstâncias bastante diferentes. Vindo de um background pessoal e profissional completamente distinto daquele de Mattoso Câmara, Jakobson aportou nos Estados Unidos internacionalmente reconhecido pelas suas publicações em diversas áreas da lingüística. Logo que chegou, foi-lhe atribuída a cátedra de filologia eslava na Faculdade de Letras e Instituto de Filologia e História Oriental e Eslava, afiliada à École Libre, cargo que manteve de 1942 a 1946 (Jakobson \& Pomorska 1983: 40-41).

Embora compartilhando o princípio da liberdade acadêmica que caracterizou a New School desde sua fundação em 1917, o corpo docente da École Libre sempre se considerou como apenas provisoriamente sediado em Nova Iorque, tanto é que, assim que terminou a guerra, praticamente todos voltaram para a Europa (cf. Rutkoff \& Scott 1986:171). Durante a guerra, entretanto, os membros da École participaram ativamente da vida intelectual da New School, e, como se pode presumir pelos números da citação abaixo, teve sucesso imediato:

In the École Libre's first semester $[=1942]$, ten professors taught more than 300 students in forty courses. By May this had swollen to sixty-five instructors in five divisions: Letters, Law and Politics, Sciences, Oriental Languages and Philology, and Latin American Studies. Almost 1000 students enrolled in more than 200 courses. The faculty described the courses as equal as those taught at the Sorbonne or the Collège de France. This claim was supported by such courses as Roman Jacobson's [sic] 'Linguistique Générale', Henri Bonnet's 'Problèmes d'organization internationale,' Claude Lévi-Strauss's 'Ethnographie générale', Georges Gurvitch's 'La Sociologie Française', and Raoul Aglion's ‘Droit comparé'. (Rutkoff \& Scott 1986: 155-156)

Mas era tempo de guerra e, como todos, a intelectualidade européia e americana tinha desafios enormes a enfrentar, incluindo a dificuldade de obter posições estáveis na Universidade (v. por ex., Jakobson 1979:163; 
Halle 1988:738; Murray 1994:216). Presumivelmente, assim se explicam os contatos que Jakobson mantivera com a Universidade de São Paulo no início dos anos 40, certamente por sugestão de Lévi-Strauss. Com efeito, em carta de 15 de janeiro de 1973 a Ataliba Teixeira de Castilho (n. 1937), Jakobson explicou os (prováveis) motivos da sua não-contratação na época:

Dear Professor de Castilho,

I just returned from long trips and found your letter of January 4. To your question I must answer that when, shortly after coming from Sweden to New York in 1941, and working from 1942 until the end of the war in the École Libre des Hautes Études in New York, together with Claude Lévi-Strauss, I was, about 1942 or '43, asked by the latter whether I would accept a possible offer from the University of São Paulo, a professorship in classical philology and general linguistics, and I expressed interest for this project; but as far as I remember, for some financial question the possibility of new chairs and invitations to São Paulo was indefinitely postponed. In the meantime I accepted a visiting, and later permanent, professorship at Columbia University, New York. With warm reminiscence of our Brazilian days of 1968, and with best wishes,

Yours sincerely, Roman Jakobson ${ }^{1}$

Infelizmente para a incipiente comunidade de lingüistas brasileiros essa tentativa não se concretizou. Somente muitos anos mais tarde, em 1968, Jakobson visitou a Universidade de São Paulo durante uma estada de um mês ao Brasil.

Quaisquer que tenham sido as razões, o fato é que no início dos anos 1940, acidentes de história pessoal reuniram Mattoso Câmara e Roman Jakobson, não no Brasil, nem na Europa, mas, 'no exílio', na cidade de Nova Iorque.

\section{As aulas sobre o som e o sentido}

De acordo com os catálogos da École Libre, conservados no MIT Institute Archives e Special Collections (Caixa 2, arquivos 5, 6, 7 e 10), a escola oferecia a cada semestre cursos abertos para o público em geral, e cursos

1 Meus agradecimentos a Ataliba T. de Castilho pela cópia da carta. 
fechados para aqueles ligados a um dos seus programmes de licence. No ano de 1942, além das seis conferências inaugurais sobre 'o som e o sentido', Jakobson proferiu um curso fechado em lingüística geral e outro em fonologia (Caixa 2, arquivo 10). Contrariamente ao que está sugerido no prefácio de 1978 à versão inglesa do livro do mesmo nome, e também em Joseph (1989) e Falk (1995a), nenhum desses cursos poderia ter sido assistido por Mattoso Câmara, que só viajou para os Estados Unidos no ano seguinte, 1943.

Os catálogos da École Libre nos arquivos do MIT atestam que outra série de conferências em lingüística geral foi ministrada por Jakobson no último trimestre de 1943 e no primeiro de $1944,{ }^{2}$ o que cobre exatamente o período da estada de Mattoso Câmara. As anotações feitas por Mattoso Câmara sobre este curso diferem bastante, entretanto, da versão das lições ‘sobre o som e o sentido' publicada por Jakobson, em 1942.

Confrontando as anotações de Mattoso Câmara com as listas arquivadas no MIT, pode-se presumir facilmente o que houve. Jakobson de fato ministrou um curso de lingüística geral, pela segunda vez, no semestre acadêmico de 1943-1944, não na École Libre, mas sim na Universidade de Colúmbia, onde ele começou a ministrar aulas exatamente nesta ocasião, como professor visitante do Departamento de Línguas Européias Orientais. Este curso inaugural na Colúmbia, também 'sobre o som e o sentido', foi aquele efetivamente seguido por Mattoso Câmara e registrado no seu caderno. Esta disparidade de datas foi um pequeno e intrigante detalhe com que me deparei logo no início da pesquisa e que precisava ser clarificado. A rigor, ele não muda o fato mais relevante, identificado tanto por Joseph quanto por Falk, que Mattoso Câmara tinha, de fato, sido um dos scholars que assistira às primeiras aulas de Jakobson na América do Norte.

\footnotetext{
2 O curso de lingüística geral ministrado por Jakobson na École Libre, no semestre acadêmico 1943-1944 foi precedido de um segundo curso em fonologia e alternado com várias conferências sobre literatura tcheca e russa. Nos anos seguintes, 1945 e 1946, ele proferiu conferência principalmente em língua e literatura eslavas. A última anotação sobre um curso em lingüística geral que eu pude localizar - Les Sons et le Sens. Introduction à la Linguistique Générale - data de 1947. Não há evidências de que este curso tenha sido efetivamente ministrado.
} 


\subsection{As anotacōes de Mattoso Câmara de 1943-1944}

Lendo o caderno de Mattoso Câmara, presume-se que as séries de aulas ministradas por Jakobson simultaneamente na École Libre e na Universidade de Colúmbia naquele semestre de 1943-1944 eram complementares. Em Colúmbia, foram discutidas as bases teóricas da sua abordagem e os princípios que governam o tratamento da dimensão fônica da linguagem. Na École, Jakobson ilustrou a teoria e a aplicou à descrição do sistema fonológico de cinco línguas: ramarama, uma língua brasileira falada na região do rio Madeira, russo, português do Brasil, yiddish e inglês americano.

As anotações sobre o curso da Colúmbia começam em 26 de outubro de 1943 - a rigor, esta foi a segunda conferência da série - e continuam, semanalmente, até 18 de janeiro de 1944. Parte das notas se referem ao esboço histórico traçado por Jakobson sobre os avanços e os limites da fonética, tanto articulatória, quanto acústica. A principal colocação de Jakobson, neste sentido, era de que a fonética deveria ser colocada a serviço da fonologia ou da fonêmica, "como se prefere chamar aqui nos Estados Unidos”, a verdadeira disciplina lingüística, e a grande 'descoberta' feita por Mattoso Câmara em Nova Iorque. O ponto central das anotações de Mattoso sobre o curso na Colúmbia foram, pois, reservadas para a fonologia de Jakobson, definida como o estudo sistemático dos sons do ponto de vista da função que eles exercem na linguagem, e pela discussão sobre as propriedades gerais dos fonemas, valores puramente negativos, a serem definidos em termos de traços distintivos.

Complementarmente, as notas de Mattoso sobre as 12 aulas ministradas na École Libre, entre 8 de outubro de 1943 e 14 de janeiro de 1944, desenvolveram tópicos de caráter eminentemente práticos. Um pequeno grupo de alunos (Lévi-Straus mais uma vez entre eles) aplicou o método de Jakobson à descrição de diferentes sistemas fonêmicos. Os dados do ramarama foram retirados do vocabulário coligido por Lévi-Strauss. Para a análise das outras línguas, Jakobson baseou-se nos dados publicados disponíveis. De acordo com as notas de Mattoso, os dados do russo foram extraídos de Boyanus (1935); os dados do português de Dunn (1928) e Hall (1943 a, b); e os do inglês, de Bloch \& Trager (1942). Não há menção sobre as fontes do yiddish. 
Uma pequena parte das anotações de Mattoso reproduziram os comentários de Jakobson sobre o trabalho de alguns de seus predecessores, notadamente sobre Jan Baudoin de Courtenay (1845-1929) e Ferdinand de Saussure (1857-1913), e sobre alguns de seus contemporâneos, como Trubetzkoy, Bloomfield, Bloch e Trager. Pelas notas de Mattoso Câmara reconhecem-se as críticas de Jakobson ao psicologismo de Baudoin, ou à definição de fonema de Trubetzkoy - para quem o fonema era um fato puramente de langue - ou à afirmação de Bloch e Trager (1942) de que fonemas são "classes de sons foneticamente semelhantes". Para Jakobson, e deste momento em diante também para Mattoso Câmara, fonemas eram um valor invariante de uma classe de sons, um feixe de traços - ou "a bundle of distinctive features" em termos bloomfieldianos (1933:79) - em oposição binária.

A rigor, as observações e críticas de Jakobson não constituem tópicos autônomos no caderno de Mattoso, mas estão disseminadas pelas anotações das diversas aulas a que assistiu e pelas notas que tomou das quatro reuniões do Círculo Lingüístico de Nova Iorque de que participou. Os conflitos da vida intelectual americana dos anos 1940 tiveram repercussões interessantes para a historiografia lingüística brasileira. Por essa razão, além dos tópicos relativos às aulas de fonologia de Jakobson e do seu método estrutural registrados por Mattoso Câmara, retomarei alguns desses comentários na parte final do texto.

\subsection{Fonética e Fonologia}

Pode-se reconhecer nas anotações de Mattoso Câmara sobre o curso na Colúmbia as mesmas colocações do texto 'sobre o som e o sentido' de 1942, publicado somente em 1976. Fazendo a revisão dos progressos em fonética acústica e articulatória, Jakobson preparou o terreno para propor uma teoria fonológica baseada nas relações entre os termos, e não nos termos em si mesmos. O pano de fundo da discussão de Jakobson é, de um lado, o que Mattoso registrou como o empiricismo ingênuo dos neogramáticos, e de outro, o psicologismo de Baudoin de Courtenay. Argumentando contra ambos, Jakobson reivindicou um "conceito meramente funcional de fonema” (Colúmbia, 6a. aula, 30/11/1943) 
Neste sentido, dois problemas relativos à fonética articulatória foram destacados por Mattoso Câmara em seu caderno. O primeiro diz respeito à dificuldade em determinar exatamente a que pontos do contínuo do aparelho fonador os fonemas, enquanto unidades discretas, correspondem. $\mathrm{O}$ segundo, inter-relacionado, se refere à dificuldade do lingüista de capturar as relações orgânicas entre os sons levando em consideração apenas aspectos articulatórios. Se observasse o efeito acústico da fala, o lingüista poderia perceber melhor as relações que existem, por exemplo, entre os sons labiais e os velares, de um lado, e entre os palatais e os dentais, de outro. No caso das labiais e das velares, sua emissão não produz qualquer obstáculo na região do palato. Em conseqüência, o ressonador, i.e., a cavidade oral, é indivisa. Dessa maneira, embora articulados em pontos bastante diferentes do aparelho vocal, os dois sons têm o mesmo efeito 'sombrio' (dark). É essa a razão por que na história de muitas línguas um som velar se transformou em um som labial, por exemplo [c] se tornou [p] em romeno, por ex. lacte $>$ lapt (Colúmbia, 2a. aula, 26/10/1943).

A fonética acústica, tal como praticada desde o século XIX, não apresentou melhores alternativas de análise, para o Jakobson de 1940. O progresso neste campo, lê-se nas notas de Mattoso, foi obtido mais pela atuação de psicólogos e físicos, já que a lingüística, dominada pelos neogramáticos, havia alijado a acústica do seu interesse. Na 3a. aula de Colúmbia (9/11/ 1943), lê-se no caderno de Mattoso o seguinte comentário:

A fonética acústica caiu no mesmo erro da fonética motora decompondo demais sem encontrar os traços essenciais e pertinentes dos sons da fala; pode reproduzi-los com felicidade como na máquina de falar de Bell, a qual faz hábeis combinações, partindo apenas de vinte elementos acústicos; mas não sabe interpretar.

As detalhadas notas de Mattoso Câmara refletem a abrangência dos comentários de Jakobson sobre o desenvolvimento das duas disciplinas fonética acústica e articulatória - desde o século XVIII. Foi certamente durante essas aulas que Mattoso teve notícia de três gerações de foneticistas. Paul Menzerath (1883-1954) e Armando Lacerda (b. 1902), Edward Scripture (1864-1945), Pierre Rousselot (1846-1924), Hermann Gutzmann (1846-1924), Christoph Hellwag (1754-1835), Carl Stumpf (18481936) e Wolfgand Köhler (1898-1967) são alguns dos nomes incluídos na bibliografia dos Princípios da segunda edição (1954) em diante. Embora reconhecendo o avanço técnico nesses domínios, o foco de Jakobson era 
mostrar que os estudos fonéticos, tanto articulatórios quanto acústicos não haviam conseguido, até o momento, "reencontrar a unidade dentro da aparente variedade" (Colúmbia, 3a. aula, 9/11/1943).

Estes dois diferentes níveis de análise e representação do som da fala, o material e o funcional, não eram de forma alguma óbvios para a audiência de Jakobson há mais de cinqüenta anos. Lévi-Strauss, por exemplo, na sua retrospectiva, revela que sua expectativa ao assistir às aulas de Jakobson era encontrar um sistema adequado de notação para os dados das línguas brasileiras que havia colhido. Em vez disso, o que encontrou, nas suas próprias palavras, foi algo diferente e muito mais importante, foi "the revelation of structural linguistics" (prefácio a Jakobson 1978[1976]:xi). Mattoso Câmara sofrera, sem dúvida, impacto semelhante.

\subsection{Os traços distintivos}

Os exercícios propostos por Jakobson na École Libre naquele semestre de 1943-1944 consistiam em determinar quais sons das línguas sob análise tinham uma função semântica diferencial, i.e., constituiriam seu sistema fonológico, e quais não, sendo apenas meros detalhes fonéticos. Os fonemas foram então definidos como "a soma das qualidades fônicas que servem para diferenciar as palavras” (1a. conferência, École Libre, 8/10/1943).

Em cada uma das línguas, Jakobson estabeleceu, em primeiro lugar, a posição em que cada som ocorria nos limites da palavra, ou seja, inicial, medial ou final. O passo seguinte consistiu em atribuir aos sons-ocorrência um certo conjunto de traços físicos, como nasalidade ou oralidade, oclusão ou constrição, sonoridade ou não sonoridade, e assim por diante, e identificar quais exerciam papéis distintivos. A análise sugeria correspondências constantes entre os sons consonantais que Jakobson dispunha em forma de padrões triangulares, como estes das oclusivas e fricativas do Português do Brasil:

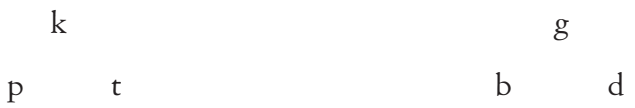

Fig. 1 - Quadro das oclusivas no Português do Brasil em posição inicial (de acordo com Jakobson, 6a. conferência, École Libre 12/11/1943) 
$\mathrm{O}$ primeiro triângulo associa as velares $[\mathrm{k}, \mathrm{g}]$ às labiais $[\mathrm{p}, \mathrm{b}]$ e às dentais $[t, d]$, em oposição ao segundo tipo de consoantes, v. Fig. 2, que associa as alveolopalatais $[\mathrm{x}, \mathrm{j}] \mathrm{e}$ [s, a] às labiodentais $[\mathrm{f}, \mathrm{v}]$, sejam surdas, sejam sonoras. ${ }^{3}$

Este tipo de arranjo 'orgânico' corresponde ao que Jakobson chamou a consciência fonológica do falante, opondo, simetricamente, em primeiro lugar, os sons posteriores aos sons anteriores. Nos sons velares e palatais, o ressonador, indiviso, se fecha ao fundo da boca, i.e., na entrada da corrente de ar, em oposição aos sons dentais e labiais, cujo ponto de articulação está localizado na frente da caixa de ressonância, i. e., na saída da corrente de ar.

Do ponto de vista metodológico foi uma solução bastante original, já que o que Jakobson estava propondo era que os sons consonânticos, tradicionalmente ordenados em um continuum unidimensional, fossem descritos em termos de oposição binária, também do ponto de vista articulatório (v. Halle 1977).

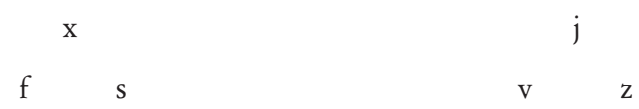

Fig. 2 - Quadro das fricativas do português do Brasil em posição inicial (École Libre 6a., 12/11/1943)

Do ponto de vista auditivo, as oposições são igualmente binárias: labiais e velares, articuladas em extremos opostos do aparelho vocal, produzem um som relativamente mais baixo, sombrio [dark] e grave, diferente das palatais e dentais, que produzem um som de timbre relativamente mais alto, percebido como mais claro e mais agudo. Além disso, as consoantes da Fig. 2 são estridentes, devido ao obstáculo suplementar dos dentes inferiores, que bloqueiam a corrente de ar uma segunda vez à saída da boca. Deste ponto de vista, as consoantes da Fig. 1 são 'doces' [mousse]. $\mathrm{O}$ padrão resultante foi estabelecido, não com base na oposição articulatória

\footnotetext{
3 A menos que diferentemente indicado, usei os mesmos símbolos utilizados por Mattoso Câmara na Fonêmica de 1953. Quando conflitantes com o IPA, o equivalente foi fornecido em nota de rodapé. Assim, no presente exemplo, [x] representa o IPA [S] e [j] o símbolo IPA [3].
} 
oclusiva-fricativa, que se torna um traço secundário, mas com base na propriedade acústica estridente-doce.

Os traços propostos "essencialmente do ponto de vista acústico que Jakobson considera primordial fonologicamente” eram, a este momento, apenas sete:

\begin{tabular}{|l|l|}
\hline Columbia (10a. conf., 11/1/1944) & École Libre (7a. conf., 19/11/1943) \\
\hline vocal: consonant & vocalisme: consonantisme \\
\hline syllabic: asyllabic & - \\
\hline dark: not-dark [light] & terne-éclatant \\
\hline - & grave: aigu \\
\hline saturated: non-saturated & - \\
\hline voiceless:voiced & fort (sourde): faible (sonore) \\
\hline nasal: oral & nasal: oral \\
\hline strident: non-strident [mellow] & strident: mousse \\
\hline- & atone: tonique \\
\hline
\end{tabular}

Fig. 3 - Os traços distintivos de Jakobson, tais como no cadernos de Mattoso Câmara (1943-1944)

Os dois sistemas de traços, como ilustrado na Fig. 3, embora ainda não completamente consistentes, claramente apontam para o desvio que seria cada vez mais nítido na fonologia de Jakobson em direção às propriedades acústicas do som e a maneira como seriam percebidos pelos interlocutores, já anunciado nas suas "Observations sur le classement phonologique des consonnes” de 1939 (Jakobson 1972[1939]), se não antes (cf. Joseph 1989, Koerner 1995, 1997).

\section{Para uma descrição estrutural do Português do Brasil}

Para se compreender o tipo de impacto que a abordagem fonêmica de Mattoso Câmara causou no Brasil do final dos anos 40, talvez seja necessário relembrar quão distante os interesses da ainda incipiente comunidade de lingüistas brasileiros estava das idéias que circulavam nos principais centros norte-americanos da época. Em continuidade com a tradição filológica portuguesa, a geração de Mattoso Câmara estava voltada para a 
história da gramática do português, a edição crítica de textos antigos, a filologia românica, a etimologia e a dialetologia (Coelho 1999), para não citar a longa tradição gramatical normativo-pedagógica.

Com raras exceções, os estruturalistas de maneira geral, tanto os europeus quanto os norte-americanos, eram totalmente ignorados pela grande maioria dos scholars brasileiros. Neste sentido, a afirmação de Mattoso Câmara, ainda em 1938-1939, sobre a prioridade da descrição do mecanismo lingüístico sobre o estudo das leis que regem sua evolução, foi isolada. Nas suas palavras, "[a]inda hoje, muitos lingüistas não se capacitaram da existência de uma ciência da linguagem sincrônica, descritiva ou estática, independente das pesquisas diacrônicas, históricas ou evolutivas." (Mattoso Câmara 1939: 25.99). Para Mattoso Câmara, neste momento, a tarefa principal da lingüística estática era o estudo do sistema fonético das línguas, incluindo o estudo dos órgãos da fonação, suas unidades indivisíveis, que ele chama fonemas, e sua combinatória; e alguns traços fonatórios que ele considera essenciais, como a quantidade, a intensidade e a altura. A este estudo de natureza fonética, Mattoso opôs o estudo da atividade lingüística propriamente dita, entendida por ele como o estudo do sistema morfológico e o estudo da frase (Mattoso Câmara 1941: 24).

As sucessivas revisões dos Princípios nos oferecem hoje um material privilegiado de observação do processo gradual de construção teórica na reflexão de Mattoso Câmara, ou talvez, neste caso, de articulação entre uma nova teoria e os dados lingüísticos disponíveis. Se compararmos, por exemplo, as edições de 1941 e a de 1954, podemos observar claramente a reviravolta funcional que se opera na sua reflexão lingüística. Na primeira citação, Mattoso justifica seu interesse pelo estudo da variação fonética, mencionando o seu papel diacrônico; na citação seguinte, como se observa, ele faz referência apenas à funcionalidade da variação do ponto de vista sincrônico. Apesar do uso do termo fonêmica, a menção de Mattoso Câmara, na segunda citação, aos aspectos acústicos e as referências que faz à perspectiva do receptor na análise dos sons lingüísticos derivam-se, claramente, da fonologia de Jakobson.

Seria insensato, entretanto, à lingüística desprezar a minuciosa observação da articulação de cada fonema e as variações ocorrentes individuais, que não têm valor lingüístico no estado atual da língua, porque, não raro, condicionam elas no âmbito diacrônico, modificações em elaboração no sistema fonético, com o aparecimento de novas 'idéias fônicas diferenciais', para servirmo-nos da lapidar expressão de Trubetzkoy. (Mattoso Câmara 1941: 26, o grifo é meu) 
Seria, entretanto, insensato desprezar a minuciosa observação dos sons da fala, com as suas articulações e variações acústicas que não têm função lingüística no estado atual da língua. É na fonética, como estudo natural do que exatamente se pronuncia e se ouve, que tem de apoiar-se a fonêmica para depreender daí o contigente que lingüística mente funciona. (Mattoso Câmara 1954: 37, o grifo é meu)

É verdade que já na edição de 1941 dos Princípios lêem-se várias referências à concepção do fonema de Trubetzkoy como 'idéias fônicas' (Lautvorstellungen), assim como à concepção dos padrões sonoros de Sapir (v. Mattoso Câmara 1941: 25-16). Mesmo assim, as primeiras abordagens de Mattoso Câmara dos sons do português são claramente '-éticas', e seu quadro principal de trabalho é o proposto por Maurice Grammont (18661946) no seu Traité de phonétique, de 1933, e por Carlo Battisti (1882-1976), no seu Fonetica generale, de 1938. Foi somente nos textos que escreveu depois do seu convívio, ainda que curto, com Jakobson, que Mattoso desenvolveu suas reflexões sobre a teoria e a prática de análise lingüística baseadas no conceito de valor diferencial funcional.

\subsection{A descrição fonêmica do português do Brasil}

Com exceção do tateante exercício de Jakobson, feito em sala de aula, na École Libre, em 1943, nunca publicado, e dos pequenos textos de Hall (1943 a, b), da monografia parcial de Sten (1944) e do estudo, também parcial de Reed \& Leite (1947), a interpretação fonêmica de Mattoso Câmara foi absolutamente pioneira na tradição de estudos do português, incluindo-se aqueles feitos em Portugal. Antes de ser publicado como livro em 1953, dois dos três estudos que fizeram parte da sua Fonêmica, foram publicados em 1949 no Boletim de Filologia do Rio de Janeiro. "Para o estudo da fonêmica portuguesa: Os fonemas em português" (Mattoso Câmara 1949a), publicado como o capítulo dois do livro, revisto a partir das observações de Garvin (1950). O segundo, mais teórico, "Para o estudo da fonêmica portuguesa: Fonética e fonêmica” (Mattoso Câmara 1949b), publicado como o capítulo um do livro. ${ }^{4}$

\footnotetext{
4 O terceiro capítulo do livro, "A rima na poesia brasileira (aplicação literária da fonêmica)", assim como os estudos estilísticos não são aqui comentados por estarem fora do escopo do presente estudo.
} 
A descrição de Mattoso Câmara de 1953 foi baseada no que definiu como a pronúncia coloquial tensa do Rio de Janeiro e consistiu basicamente em um sistema fonêmico de 26 unidades, 7 sons vocálicos (a rigor 9, já que Mattoso considera também os não silábicos) e 19 consonânticos. Neste sentido, o sistema de Mattoso representava uma solução descritivamente econômica e elegante, se comparada àquelas em circulação, como a de Gonçalves Viana (1892), para citar apenas uma das freqüentemente mencionadas pelo próprio Mattoso Câmara.

A análise de Mattoso do sistema vocálico do português foi baseada no acento. Ele identificou 7 sons silábicos: [a] [è] [e] [i] [ò] [o] [u], e 2 nãosilábicos [y] e [w] (cf. vou [vow], vôo [vou]; sois [soys], soes [sois]) em posição tônica, levando em consideração o seu ponto de articulação, o grau de abertura bucal e o arredondamento dos lábios (cf. Mattoso Câmara 1953a: 73). ${ }^{5}$ Contrariamente a Hall (1943 a, b) e Lüdtke (1951), Mattoso rejeitou o valor fonêmico da oposição entre o [a] anterior retrátil e o [â] central retrátil , como em bradar e bramar. Ele desconsiderou o contra-exemplo aparente da distinção entre as formas da primeira conjugação no presente, como em amamos [â], e amamos [a], no passado, artificial, segundo ele, e não ocorrente na variedade falada do Rio de Janeiro (Mattoso Câmara 1953 a: 70-71).

Ele observou que em posições átonas o sistema poderia variar de 3 a 5 fonemas. Em posição pretônica, no dialeto sob análise, as oposições [e] [è] e [o] [ò] são neutralizadas, e em posição final, todas as vogais anteriores são reduzidas ao arquifonema [I], e os posteriores ao arquifonema [U].

Esta flutuação, entretanto, ainda que não casual, como atesta sua detalhada exposição, não foi interpretada por ele como fonêmica: "[a]s realizações de posição átona são alofones, decorrentes do ambiente prosódico em que se acham" (Mattoso Câmara 1953a: 83).

As maiores controvérsias na sua interpretação do sistema vocálico do português foram as relativas às nasais. Para Mattoso, não havia contraste entre uma vogal nasal e uma vogal seguida de consoante nasal como há no francês bon/bõ/ em oposição a bonne /bon/. Uma vez mais contrariamente à interpretação de Hall, e em concordância com Jakobson, Mattoso excluiu as vogais nasais do sistema do português, explicando variações como/-um/

Os símbolos correspondentes ao IPA são: [è] para [ع]; [ò] para [o] e [â] para [ə]. 
/-un/ /-ung/ (cf. Hall 1943a) como realizações de um arquifonema nasal, foneticamente condicionado pelo contexto: realizado como [m] antes das labiais, como [n] antes das dentais e como [n] antes das velares (cf. Mattoso Câmara 1953a: 92). Esta solução motivou uma das mais agudas críticas de Garvin:

The whole terminology of 'neutralization' and 'archiphonemes' is, of course, essentially a way of avoiding clear statements that some phonemes appear in some positions where others do not, and that, when one has left the phonemic level of analysis and gone on to morphophonemics, one may discover relationships between certain phonemes in terms of these distributional gaps. (Garvin 1950: 95)

Foi em resposta a esta e também a outras críticas de Garvin (ibid.) que Mattoso reviu sua primeira interpretação do sistema consonântico do português. Na versão de 1949 da sua fonêmica, ele propôs um sistema de 18 sons, no qual a vibrante simples 'r', em posição intervocálica, foi interpretada como uma variante da vibrante múltipla 'rr' - como ocorre em caro e carro - e não como um fonema distinto. Sua argumentação era engenhosa: o encontro ' $r r$ ' representava, na sua opinião, a junção prosódica de um ' $r$ ' pós-vocálico, seguido de outro 'r' em posição inicial, que é sempre múltiplo, em português. Em outras palavras, o 'r' pós-vocálico, foneticamente perceptível em ar roxo, por causa da divisão de palavras, também existe em arrocho, mesmo se não atualizado foneticamente. Argumentos com os quais seus leitores não concordaram absolutamente (v. também Lüdtke 1951: 354).

Concedendo às críticas, Mattoso (1953a) apresentou uma segunda versão da sua interpretação do sistema consonântico do português, com 19 unidades, em que ' $r$ ' e 'rr' representariam dois fonemas diferentes, que tinham a peculiaridade de criar uma distinção fonêmica somente em posição intervocálica. Mattoso descreveu simetricamente as consoantes em padrões ternários, de acordo com a natureza da obstrução envolvida na sua articulação, o ponto da articulação e o papel das cordas vocálicas.

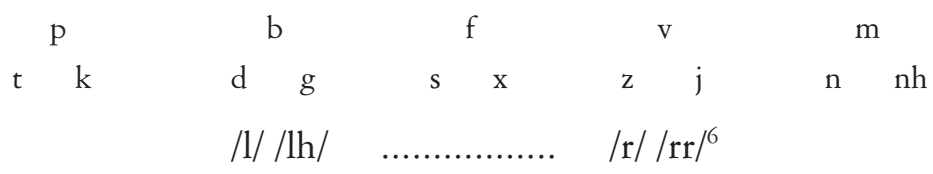

Fig. 4 - As consoantes do português do Brasil de acordo com Mattoso Câmara (1953a)

6 No IPA, respectivamente: [nh] para $[\mathrm{n}] ;[\mathrm{lh}]$ para $[\lambda]$; $[\mathrm{r}]$ para $[\mathrm{r}]$ e $[\mathrm{rr}]$ para $[\mathrm{r}]$ 
A análise das consoantes de Mattoso foi claramente inspirada, como se vê, nas aulas de Jakobson de 1943. Mattoso propôs quatro categorias de consoantes: oclusivas, fricativas, nasais e líquidas, surdas e sonoras (Mattoso Câmara 1953a: 101 ss.). Exceto pelas líquidas /l/ /h/ /r//rr/, cada categoria tem três consoantes, que ele dispõe nos ângulos dos triângulos: as labiais $[p, b, f, v, m]$ no vértice e as não-labiais embaixo. As não-labiais estão subdivididas em dois outros grupos: as que se articulam com a parte anterior da língua [t, d, s, z, n], que ele localiza no ângulo inferior esquerdo dos triângulos, e as que articulam com a parte posterior da língua, $[k, g, x, j$, nh], dispostas no ângulo inferior direito.

O mesmo padrão se repete para as consoantes palatalizadas: as fricativas não labializadas [s] [z], relativamente anteriores, são dispostas no ângulo esquerdo do triângulo; no ângulo oposto estão [x] [j] relativamente posteriores (cf. cf. sim / $/ \tilde{\mathrm{s}} /$ - chim / $\tilde{\mathbf{x}} / /$, zelo /zelu/ - gelo /jelu/). O mesmo se aplica às líquidas e nasais mouillés [lh] [nh], relativamente posteriores, opostas às não-mouillés [1] [n] (cf. olhos - óleos). Ao invés de uma lista de sons linearmente dispostos, Mattoso é bem-sucedido em revelar um sistema consonântico simétrico e orgânico do português, 'où tout se tient'.

\subsection{Fonêmica e Fonologia}

Mattoso Câmara abre a sua Fonêmica de 1953 declarando explicitamente que seu quadro de trabalho era a fonologia européia tal qual proposta pela Escola de Praga. Seu ponto principal foi contrastar a perspectiva dos foneticistas tradicionais, "que viam no estudo dos sons lingüísticos uma ciência natural fundamentada na física e na fisiologia”, com a dos fonólogos, "que vê[em] nos sons da língua elementos da constituição das palavras com uma função gramatical nítida (Mattoso Câmara 1953a:13).

No histórico que se segue, Mattoso discute em detalhe os vários (e freqüentemente também contraditórios) referentes cobertos pelos termos 'fonologia' e 'fonética', principalmente nas tradições que, via França e Portugal, tiveram alguma recepção no Brasil, como o trabalho de Eduard Sievers (1850-1932), Henry Sweet (1845-1912), Otto Jespersen (18601943), Paul Passy (1859-1940) e Aniceto dos Reis Gonçalves Viana (18401914). 
A observação inicial de Mattoso Câmara tem que ser entendida no contexto acadêmico do Rio de Janeiro dos anos 1950. Ele se dirigia a uma audiência que, embora versada em assuntos lingüísticos, não via ainda com clareza a especificidade da sua abordagem fonêmica em relação à descrição fonética tradicional. Mesmo porque, o interesse desta geração estava mais para o mapeamento das diferenças de pronúncia entre o português europeu e o português do Brasil do que na sua convergência, enquanto sistema. Construir uma ponte entre este tipo de descrição fonética e a abordagem funcional que tencionava aplicar à descrição do português, mantendo, ao mesmo tempo, a especificidade de ambas, certamente não era uma tarefa fácil para Mattoso neste momento.

Neste momento, escolher o termo 'fonologia', empregado por Trubetzkoy, autor já conhecido da comunidade acadêmica brasileira, era admitidamente problemático para Mattoso, na medida em que o termo já tinha sido usado para referir a outros tipos de estudo do som, e nem sempre de forma consistente. Por essa razão, pondera Mattoso, ele preferia usar o termo 'fonêmica', originário da Escola Norte-Americana, para designar o tipo de estudo que ele pretendia, até então desconhecido do público brasileiro. Como ele claramente afirma: "Tem-se assim antes de tudo a grande vantagem de uma designação nova para uma noção nova, sem conotações anteriores ou paralelas que lhe possam perturbar a compreensão" (Mattoso Câmara 1953a:17).

Embora Mattoso estivesse perfeitamente ciente de que os dois quadros estruturalistas de trabalho, os assim chamados europeu e norte-americano, pudessem ser distinguidos um do outro sob vários aspectos, ele não via diferenças substanciais entre o funcionalismo inaugurado por Trubetzkoy e o estruturalismo proposto por Sapir. Ao contrário, na sua leitura, as proposições de Saussure, Trubetzkoy, Sapir, Jakobson e Bloomfield não só não eram incompatíveis, como complementavam umas às outras. Tanto é que Mattoso é não só o tradutor de Sapir (1954[1938], 1961) e Jakobson (1967), como também resenhou os textos de Trubetzkoy e Jakobson mais de uma vez (Mattoso Câmara 1946a, b, 1949c), além de outros lingüistas norte-americanos, ao longo das décadas de 50 e 60.

Assim, para Mattoso, não havia absolutamente contradição em denominar este tipo praguiano de fonologia, de 'fonêmica'. Tampouco em se valer - como fez - dos conceitos de 'sílaba', 'juntura' e 'distribuição com- 
plementar', típico das análises (pós)bloomfieldianas (cf. Hall 1943a, b; Hockett 1993), lado a lado dos conceitos de 'arquifonema' e 'neutralização', que se originaram na tradição de Praga, e do conceito de fonema como 'feixe de traços distintivos', difundido em ambas tradições. O que parecia ser pertinente para Mattoso neste momento era introduzir no estudo gramatical do português o conceito de fonema como unidade funcional. Embora a ciência não tenha nacionalidade, seguir uma orientação européia ou norte-americana logo se tornaria um divisor de águas importante da ainda incipiente comunidade de lingüistas brasileiros 'modernos' (Altman 1998).

\section{Os lingüistas e os círculos lingüísticos}

Se tensões entre as tradições européia e norte-americana de estudo da linguagem ecoavam na então longínqua Rio de Janeiro de 1940, não é difícil imaginar o que se passava em Nova Iorque, onde um grande número de refugiados europeus inundava o mercado de trabalho norte-americano (v. Robert Hall in Murray 1994: 216; mas v. também Jakobson 1979, Halle 1988, e Falk 1995a).

Em um sentido, a criação do Círculo Lingüístico de Nova Iorque Cercle Linguistique de New York - em 1943, nomeado a partir de seus antecessores no gênero em Moscou, Praga, Copenhagen e Paris, pode ser interpretado como um esforço de superar algumas dessas diferenças. Fundado pelos lingüistas ligados à École Libre e pela Société Linguistique de Paris, o Círculo também acolheu muitos lingüistas americanos, vindos das universidades de Colúmbia, City College, Fordham, New York, Princeton, e também do Departamento de Guerra americano (Fowkes 1994: 2). Não totalmente por acaso, talvez, foi eleito como seu primeiro presidente um scholar que era membro do corpo docente da Universidade de Colúmbia e também da École Libre, Henri-François Muller (1879-1959), em cujas palavras:

The strengthening of this co-operation [between American and European linguists] is one of the fundamental tasks of the Linguistic Circle of New York. In present-day linguistic thought there should be no room for either European or American isolationism that merely betrays in its protagonists a circumscribed scientific horizon and a harmful complacency. (Muller 1945:3) 
Se as diferenças entre uns e outros não se resolveram nas reuniões do Círculo, pelo menos havia algo em todos concordavam: nenhum dos seus fundadores se identificava com a ortodoxia neo-bloomfieldiana dominante na lingüística norte-americana - seja a este momento, seja nas décadas seguintes (cf. Murray 1994: 215). Era também o caso de Mattoso Câmara. Embora usualmente discreto e moderado nas suas observações, Mattoso certamente deixou escapar aqui e ali sinais do clima (nem sempre amistoso) de ebulição intelectual da lingüística norte-americana dos anos 1940. Com efeito, Murray corrobora de forma direta, o que apenas se vislumbra nas anotações de Mattoso em seu caderno:

Studies in Linguistics, edited by Bloch's cronies George Trager and (for the first five volumes) Martin Joos became the sectarian organ of extremist Tragerian linguistics. [...] Those who published in SIL generally eschewed consideration of semantics in phonological analysis, regarded the 'levels' of phonology, morphology and syntax as necessarily analytically separate, were dogmatic that they carried the one true 'scientific' and 'theoretical' linguistics, tended to ignore Europeans structuralist linguistics and tended to display hostility to scholars trained in Europe such as Roman Jakobson (1896-1982) and André Martinet (b. 1908), who edited and published in Word, the official journal of the Linguistic Circle of New York." (Murray 1991: 25-26)

O primeiro número de Word, fundado em 1945 (v. Martinet 1994) listou os temas das oito primeiras reuniões do Círculo, que ocorreram entre outubro de 1943 e maio de 1944. Por ele, também, fica-se sabendo que os resumos dessas discussões foram publicados em boletins mimeografados do Círculo que, aparentemente, se conservaram apenas em coleções particulares (Fowkes 1994: 3). O caderno de Mattoso Câmara traz comentários extensivos sobre as discussões que se desenvolveram nas quatro primeiras reuniões do Círculo, que nos permite reconstruir parcialmente o clima dos debates.

Lê-se nas anotações de Mattoso que a primeira reunião, ocorrida nas dependências da École Libre, foi presidida por Henri-François Muller e pelo então diretor da École, o historiógrafo da literatura Gustave Cohen, que evocou, na sua fala, a Societé Linguistique de Paris e a memória de Antoine Meillet. A seguir, Louis H. Gray, da Universidade de Colúmbia, falou em nome dos scholars americanos. Se referências a outras figuras proeminentes foram feitas nesta ocasião, como lembra Muller (1945:3), Mattoso Câmara não registrou. Entretanto, há alguns detalhes interessantes sobre os deba- 
tes que ocorreram no Círculo, como o provocado pela intervenção de Giuliano Bonfante (n. 1904) de Princeton, sobre o tema "L'évolution linguistique et le developpement de la mentalité humaine". O cerne da comunicação de Bonfante era a defesa da idéia de que a 'evolução' das formas lingüísticas correspondia à 'evolução' das mentalidades, de primitivas a civilizadas - uma tese inaceitável, evidentemente, para o clima estruturalista em torno do qual se erigia o Círculo, não apenas da parte dos lingüistas, mas também de outros habitués das reuniões, incluindo o filósofo da ciência Alexandre Koyré (1892-1964), Lévi-Strauss e Gustave Cohen.

Mattoso Câmara foi parcimonioso nos adjetivos ao registrar as divergências de opiniões. As lembranças de Fowkes são possivelmente mais explícitas sobre o modo como alguns ânimos se exaltavam:

From the earliest meetings it became apparent that there were 'idiomatic' differences between American and European behavior in discussion and in Circle activities in general. There was a point of view on the part of some members that a speaker was fair game for personal attacks. Once or twice it even looked, or sounded, as if someone were about to be challenged to a duel. (Fowkes 1994: 3)

O caderno de Mattoso registra em algumas poucas páginas as duas reuniões seguintes. O texto de Morris Swadesh (1909-1967) sobre "The Future of Basic English in the light of Language History" (2a. reunião do Círculo, 19/11/1943), motivado pelo clássico problema da viabilidade de uma 'língua universal', no caso o inglês, e de uma 'língua artificial' (v. Falk 1995b). Os temas que se seguiram referem à homenagem de Jakobson e Herzog a Franz Boas (3a. reunião, 18/12/1943), e a fala do Capitão [Henty Lee] Smith "em substituição ao Lieutenant Charles F. Hockett sobre 'Language Study in the Global War'”, seguido do estudo de Henri Grégoire (1871-1955) da Chanson de Roland (4a. reunião, 22/12/1943). As anotações de Mattoso sobre as reuniões do Círculo terminam aqui.

A entrada de Mattoso na órbita da lingüística americana, atestada pelas referências crescentes aos scholars americanos nos textos que publicou e revisou ao longo dos anos que se seguiram à sua viagem aos Estados Unidos, mudaram profundamente sua concepção de análise lingüística e das tarefas a serem exercidas pelos lingüistas brasileiros. Não apenas Sapir e Bloomfield, mas também Hall, Twaddell, Bloch, Trager, Pike, Hockett e 
Harris foram incluídos ao lado de Saussure, Trubetzkoy, Jakobson e Martinet, na bibliografia da sua Fonêmica.

Tal e qual nas suas anotações, Mattoso Câmara foi bastante discreto ao apresentar à audiência brasileira as divergências de orientação teórica e prática dos vários grupos, 'europeus' e 'americanos', em algum tipo de conflito. A ambigüidade na orientação do seu trabalho, entretanto, acentuada pela escolha do termo fonêmica para designá-lo, teve um alto custo para a aceitação da sua proposta e posterior desenvolvimento. Assim é que, tanto a edição de 1949 da sua Fonêmica, quanto a de 1953 e a de 1977, póstuma, mostram claramente o débito de Mattoso para com o foneticista português Gonçalves Viana, para com o filólogo brasileiro Álvaro Ferdinando Sousa da Silveira (1883-1967), seu antigo professor e colega da Faculdade de Filosofia do Rio de Janeiro, e, sobretudo, para com Roman Jakobson e a Escola de Praga (cf. Mattoso Câmara 1968: 234). Ainda assim, Mattoso Câmara sofreu durante um bom tempo a pecha de 'americanizado' demais, qualificação freqüentemente usada de modo pejorativo por uma parte do establishment filológico do período. Não por acaso, pois, Antenor Nascentes (1886-1971), uma figura de primeira linha nos círculos filológicos de língua portuguesa, conclui na sua resenha a Mattoso Câmara (1953a):

Foi pena que o autor, um dos pioneiros deste assunto, houvesse dado ao seu estudo o nome de fonêmica. Com certeza foi influenciado pelo inglês phonemics, já que é tão afeiçoado aos lingüistas norte-americanos... (Nascentes 1954: 301)

As mudanças na lingüística mattosiana neste momento de construção de um quadro de trabalho estrutural para a descrição do português pode ser resumida em três pontos principais: 1) a concepção de fonema como um valor lingüístico, uma unidade funcional que não pode ser confundida com o som que a manifesta, nem com a representação mental que dela faz o falante; 2) a análise e descrição dos dados lingüísticos nos limites dos sistemas sincrônicos de que fazem parte, como resultantes da oposição de traços pertinentemente distintivos; 3) a conseqüente divisão de trabalho no estudo da dimensão fônica da linguagem em duas disciplinas diferentes, fonologia ou fonêmica, de um lado, e fonética, de outro. Embora nada revolucionárias, eram idéias distantes das preocupações mais imediatas da comunidade acadêmica da época. O trabalho de Mattoso Câmara foi per- 
cebido inicialmente como um exemplar da (renegada) antimentalista e positivista lingüística norte-americana.

\section{Observações finais}

Mattoso Câmara foi recontratado como professor de lingüística na Faculdade Nacional de Filosofia do Rio de Janeiro em 1947. Dez anos mais tarde, em 1957, foi trabalhar na Universidade Católica de Petrópolis e, em 1958, criou o Setor Lingüístico do Museu Nacional, ao lado do já existente Setor Dialetológico, de Serafim da Silva Neto. O setor dedicado à lingüística e o subseqüente acordo entre o Summer Institute of Linguistics e o Museu Nacional, em 1959, era um claro sinal do grau de autonomia que a disciplina começava a adquirir no país em relação à filologia.

Nos anos 1960, Mattoso Câmara foi professor visitante nas Universidades de Washington (Seattle, em 1962); Georgetown (Washington D.C, 1963-1964 e 1966); de la República (Montevidéu, em 1965) e Autônoma do México (Cidade do México, em 1968). Com a implementação oficial da disciplina em 1962 em todas as faculdades de Letras do Brasil, Mattoso Câmara ganhou notoriedade. Participou de incontáveis reuniões científicas, associou-se às sociedades lingüísticas e prestou inúmeros serviços à profissão - incluindo a fundação da ABRALIN, a Associação Brasileira de Lingüústica, em 1969.

Depois de toda a polêmica que suscitou em vida, Mattoso Câmara ganhou prestígio intelectual e institucional em todo o país. Foi eleito presidente da Associação Latino-Americana de Filologia e Lingüística (ALFAL) em 1968 e, unanimemente, aclamado o 'pai' da lingüística brasileira que havia sido injustamente tratado pelos seus contemporâneos.

O que não deixa de ser irônico. Quando a Fonêmica de Mattoso Câmara atingiu as necessárias qualificações para ser aceita como o exemplar de uma linha estrutural de investigação para o português, a geração seguinte já tinha voltado sua atenção para uma 'nova' revolução em lingüística, em que não havia lugar para qualquer fonêmica, seja de orientação européia, seja de orientação norte-americana. Conseqüentemente, não havia mais tempo para qualquer programa mattosiano de investigação, nem para o português, nem para qualquer outra língua brasileira. Os valores da geração que estabeleceu oficialmente a disciplina lingüística no Brasil dos anos 
60 mudaram rápido demais. Reconhecido mais como precursor, ou pioneiro, do que um lingüista 'moderno', Mattoso Câmara foi logo considerado ultrapassado em assuntos lingüísticos e sua Fonêmica morreu com ele, em 1970.

E-mail: altman@usp.br

\section{REFERÊNCIAS}

Altman, Cristina. 1998. A Pesquisa Lingüística no Brasil (1968-1988). São Paulo: Humanitas.

BLOCH, Bernard and George L. TRAGER. 1942. Outline of Linguistic Analysis. Baltimore, MD: Waverly Press.

Boranus, Semen Karlovich. 1935. A Manual for Russian Pronunciation. London: Sidgwick \& Jackson.

BLoomfield, Leonard. 1933. Language. London: George Allen \& Unwin. Coelho, Olga. 1999. "Filologia e Lingüística no Brasil (1940-1960): O Ponto de Vista Filológico". Boletim do GT Historiografia da Lingüística Brasileira. Plano Bienal 1998-2000. São Paulo: Humanitas.

DunN, Joseph. 1928. A Grammar of the Portuguese Language. (=Hispanic Notes \& Monographs; Portuguese series.) Washington, D.C.: National Capital Press.

FALK, Julia S. 1995a. "Roman Jakobson and the History of Saussurean Concepts in North American Linguistics". Historiographia Linguistica, 22: 3.335-367.

1995b. "Words without Grammar: Linguists and the International Auxiliary Language Movement in the United States." Language \& Communication, 15: 3.241-159.

FrançA, Angela Maria Ribeiro. 1995. Levantamento das Proposições dos Autores Citados nos 'Princípios de Lingüística Geral'. Programa de Iniciação Científica CNPq/USP, Ms.

1998. Texto e Contexto nos Escritos Lingüísticos de Mattoso Câmara (1938-1954). Dissertação de Mestrado. São Paulo/USP.

Fowkes, Robert A. 1994. "The International Linguistic Association: A subjective history". Word, 45: 1.1-17.

Garvin, Paul. 1950. Review of Mattoso Câmara 1949a. Studies in Linguistics, 8: 4.93-98.

Gonçalves Vianna, Aniceto dos Reis. 1892. Exposição da Pronuncia Normal Portuguesa para Uso de Nacionaes e Estrangeiros. Lisboa: Imprensa Nacional. 
Hall Jr., Robert A. 1943a. “The Unit Phonemes of Brazilian Portuguese”. Studies in Linguistics, 1: 15.1-6.

1943b. "Occurrence and Orthographical Representation of Phonemes in Brazilian Portuguese”. Studies in Linguistics, 2: 1.6-13. Halle, Morris. 1977. "Roman Jakobson's Contribution to the Modern Study of Speech Sounds". Roman Jakobson. Echoes of his scholarship ed. por Daniel Armstrong e C. H. van Schooneveld. Lisse: The Peter de Ridder Press.

1988. "The Bloomfield-Jakobson Correspondence, 1944-1946." Language, 64: 4.737-754.

Hockett, Charles F. 1993. "George Leonard Trager". Language, 69: 778-788.

Jakobson, Roman. 1962. Selected Writings I: Phonological studies. The Hague: Mouton. (2a. ed. ampliada, 1971.)

1967. Fonema e Fonologia. (Seleção, tradução e notas, com um estudo sobre o autor por Joaquim Mattoso Câmara.) Rio de Janeiro: Acadêmica.

1972[1939]. "Observações sobre a Classificação Fonológica das Consoantes". (Trad. de Joaquim Mattoso Câmara de "Observations sur le classement phonologique des consonnes”, 1939.) Publicado em Jakobson 1972: 65-74.

1976[1942]. Six Leçons sur le Son et le Sens. Paris: Minuit. (Prefácio de C. Lévi Strauss, reimpresso em Le Regard Éloigné, "Les leçons de la linguistique". Paris: Plon, 1983; reimpr. em Selected Writings VIII, 317-390.)

1977[1976]. Seis Lições sobre o Som e o Sentido. (Prefácio de Claude Lévi-Strauss. Trad. por Luís Miguel Cintra.) Lisboa: Moraes; São Paulo: Martins Fontes.

1978[1976]. Six Lectures on Sound and Meaning. (Prefácio de Claude Lévi-Strauss. Trad. por John Mepham.) Hassocks: Harvester Press.

1979. "The Twentieth Century in European and American Linguistics: Movements and Continuity." The European Background of American Linguistics, ed. por H. Hoenigswald, 161-174. Dordrecht: Foris.

1990. On Language. Ed. por Linda R. Waugh e Monique Monville-Burston. Cambridge, Mass.: Harvard University Press. 
Jakobson, Roman \& Krystyna Pomorska. 1983. Dialogues. Cambridge, Mass.: MIT Press.

JosepH, John E. 1989. “The Genesis of Jakobson's Six Lectures on Sound and Meaning”. Historiographia Linguistica, 16: 3.415-420.

Koerner, E.F.K. 1995. "History and Historiography of Phonetics". Professing Linguistic Historiography. Amsterdam \& Philadelphia: John Benjamins.

1997. "Remarks on the Sources of R. Jakobson's Linguistic Inspiration". Jakobson entre l'Est et l'Ouest, 1915-1939, ed. por Françoise Gadet e Patrick Sériot, 159-176. Lausanne: Université de Lausanne, Cahiers de l'ILSL, 9.

LÉvi-Strauss, Claude 1974. Tristes Tropiques. (Trad. do francês por John and Doreen Weightman.) New York: Atheneum. (1a. ed. 1955.) 1977[1976]. 'Prefácio' a Jakobson 1977, 7-17.

Llorach, Alarcos. 1962. Resenha de Mattoso Câmara 1959. Romance Philology, 15: 3. 335-338.

LÜDTKE, Helmut. 1951. Resenha de Mattoso Câmara 1949a. Boletim de Filologia, 12: 3/4.353-355. (Lisboa: Centro de Estudos Filológicos.) Martinet, André. 1994. "An Early History of Word. Volumes 1 to 25". Word, 45: 1.27-37.

Mattoso Câmara Jr., Joaquim. 1939. "Lições de Lingüística Geral”. Revista de Cultura, 25.99-104; 183-89; 216-22; 279-84; 26. 43-47; 81-86; 177-85; 27. 21-27; 83-88; 141-46; 202-8; 28. 11-17. Rio de Janeiro: Vozes.

1941. Princípios de Lingüística Geral como Fundamento para os Estudos Superiores da Língua Portuguesa. Rio de Janeiro: Briguiet. (Reimpr. em 1942.)

1945. Os Estudos Lingüísticos nos Estados Unidos da América do Norte. (=Museu Nacional. Publicações Avulsas 1.) Rio de Janeiro: Imprensa Nacional.

1946a. Resenha de Roman Jakobson, Kindersprache, Aphasie und Allgemeine Lautgesetze. (Uppsala: Almqvist \& Wiksells, 1941.) Boletim de Filologia, 1: 37-40. Rio de Janeiro: Edições Dois Mundos. (Reimpr. em Mattoso Câmara 1977[1953a]. 129-133.)

1946b. Resenha de N. S. Trubetzkoy, Grundzüge der Phonologie. (Prague, 1939.) Boletim de Filologia, 2: 97-107. Rio de Janeiro: Edições Dois Mundos. (Reimpr. em Mattoso Câmara 1977[1953a]. 117-129.) 
1949a. "Para o Estudo da Fonêmica Portuguêsa: Os fonemas em português.” Boletim de Filologia, 3: 9.1-30. (Rio de Janeiro, publicado como Capítulo II em Mattoso Câmara 1953a.)

1949b. "Para o Estudo da Fonêmica Portuguesa: Fonética e Fonêmica." Boletim de Filologia, 3: 10.71-99. (Rio de Janeiro, publicado como Capítulo I em Mattoso Câmara 1953a.)

1949c. Resenha de N. S. Trubetzkoy, Principes de Phonologie. (Trad. por J. Cantineau. Paris, 1949.) Boletim de Filologia, 3: 9.53-55. Rio de Janeiro: Edições Dois Mundos.

1953a. Para o Estudo da Fonêmica Portuguesa. Rio de Janeiro: Organização Simões. (2a. ed., preparada por Raimundo Barbadinho Neto de acordo com instruções deixadas pelo autor. Rio de Janeiro: Padrão, 1977.)

1953b. Contribuição à Estilística Portuguesa. Rio de Janeiro: Organização Simões.

1954. Princípios de Lingüística Geral como Introdução aos Estudos Superiores da Língua Portuguesa, 2a. ed. revista e ampliada. Rio de Janeiro: Acadêmica.

1959. Princípios de Lingüística Geral como Introdução aos Estudos Superiores da Língua Portuguesa, 3a. ed. revista e ampliada. Rio de Janeiro: Acadêmica. (4a. ed., 1967.)

1965. Introdução às Línguas Indígenas Brasileiras. 2a. ed. Revista e ampliada. Rio de Janeiro: Acadêmica.

1968. "Brazilian Linguistics". Current Trends in Linguistics. IV Ibero-American and Caribbean Linguistics ed. por Thomas Sebeok. Paris: Mouton.

1969. Problemas de Lingüística Descritiva. Rio de Janeiro: Vozes. 1970. Estrutura da Língua Portuguesa. Rio de Janeiro: Vozes.

1972. The Portuguese Language. (Trad. por Anthony Naro.) Chicago \& London: The University of Chicago Press.

1975 [1962]. História da Lingüística. (Trad. por Maria do Amparo Barbosa de Azevedo dos manuscritos originais em inglês, de 1962.) Rio de Janeiro: Vozes.

Muller, Henri F. 1945. "Word”. Word, 1. 3-4.

Murray, Stephen O. 1991. "The First Quarter Century of the Linguistic Society of America, 1924-1949.” Historiographia Linguistica, 18: 1.1-48. 
1994. Theory groups and the study of language in North America. A social history. Amsterdam \& Philadelphia: John Benjamins.

Naro, Anthony J. 1972. "Translator's Preface” a Mattoso Câmara 1972: VII- XIII.

Naro, Anthony \& John Reighard. 1972. "Analytical bibliography of Joaquim Mattoso Camara, Jr." (c/ index por data de publicação e por resenhas). In: Mattoso Câmara 1972.

NAsCentes, Antenor. 1954. "Resenha a Mattoso Câmara 1953a". Jornal de Filologia, 2: 300-302 (São Paulo).

Reed, David W. e Yolanda Leite. 1947. "The segmental phonemes of Brazilian Portuguese: standard paulista dialect”, publicado in Phonemics, de Kenneth L. Pike, 194-202, Ann Arbor.

Rodrigues, Aryon. 1984. "A Obra Científica de Mattoso Câmara Jr." Cadernos de Estudos Lingüísticos, 6. 83-94. (São Paulo: Universidade de Campinas.)

Rogers, Francis M. 1954. Resenha de Mattoso Câmara 1953a. Language, 30: 4.503-509.

Rutkoff, Peter M. and William B. Scott. 1986. New School: A history of the New School for Social Research. New York: Free Press; London: Collier Macmillan.

SAPIR, Edward. 1954[1938]. A linguagem: Introdução ao Estudo da Fala. Rio de Janeiro: Instituto Nacional do Livro (Trad. por J. Mattoso Câmara Jr.)

1961. Lingüística como Ciência. (Ensaio, seleção, tradução e notas de J. Mattoso Câmara Jr.) Rio de Janeiro: Acadêmica.

SAPORTA, Sol. 1960. Resenha de Mattoso Câmara 1959. Language, 36: 1.89-97.

Sten, Holger. 1944. Lês particularités de la langue portuguaise. (=Travaux du Cercle Linguistique de Copenhage, 2.) Copenhagen: Ejnar Munksgaard.

UchÔA, Carlos Eduardo Falcão. 1972. (Seleção e introdução.) Dispersos de J. Mattoso Câmara Jr. Rio de Janeiro: Fundação Getúlio Vargas.

WaUgh, Linda R. and Monique Monville-Burston. 1990. "Introduction: The Life, Work, and Influence of Roman Jakobson". Jakobson 1990: $1-45$. 